\title{
INTERCORRÊNCIA ENTRE LEUCOSE ENZOÓTICA E TUBERCULOSE EM BOVINOS LEITEIROS DO ESTADO DE PERNAMBUCO
}

\author{
E.I. Mendes ${ }^{1 *}$, L.E.H. Melo ${ }^{1}$, T.G.S. Tenório ${ }^{2}$, L.M. Sá ${ }^{1}$, \\ R.J.C. Souto ${ }^{1}$, A.C.C. Fernandes ${ }^{1}$, H.M.M. Sandes ${ }^{1}$, T.I.B. Silva ${ }^{1}$ \\ ${ }^{1}$ Universidade Federal Rural de Pernambuco, Departamento de Medicina Veterinária, Rua Dom Manoel de \\ Medeiros, s/no, CEP 52171-900, Recife, PE, Brasil. E-mail: emersonisrael@hotmail.com
}

\section{RESUMO}

\begin{abstract}
Objetivou-se com este estudo avaliar a intercorrência entre leucose enzoótica e tuberculose em rebanhos bovinos leiteiros em oito municípios do Estado de Pernambuco, pelo estabelecimento da prevalência de bovinos reagentes às provas diagnósticas específicas. Foram analisados sorologicamente 662 animais, pela técnica de imunodifusão dupla em gel de agarose e 612 foram avaliados imunoalergicamente, por meio do teste de tuberculinização. Nos 15 rebanhos examinados, as prevalências de bovinos que apresentaram positividade aos testes IDGA e tuberculina foram 32,2\% $(213 / 662)$ e $14,1 \%(86 / 612)$, respectivamente. Os resultados obtidos nesta pesquisa permitiram concluir que as doenças estudadas encontram-se amplamente disseminadas na população avaliada, com crescimento em níveis significativos da leucose, e as infecções pelo vírus da leucose bovina (VLB) e Mycobacterium bovis encontram-se ativas e em expansão, com risco do comprometimento da saúde dos rebanhos bovinos e, pelo caráter zoonótico da tuberculose bovina, das pessoas que lidam com os bovinos.
\end{abstract}

PALAVRAS-CHAVE: Mycobacterium bovis, VLB, intercorrência, bovinos leiteiros, Pernambuco.

\begin{abstract}
ASSESSMENT OF INTERCURRENCE OF ENZOOTIC LEUCOSIS AND BOVINE TUBERCULOSIS IN DAIRY COWS IN THE STATE OF PERNAMBUCO, BRAZIL. We carried out this study to evaluate the intercurrence of tuberculosis and enzootic leukosis in dairy cattle herds in 8 districts of the State of Pernambuco, Brazil, by establishing the prevalence of bovines reagent to specific diagnostic tests, and to also verify the correlation between enzootic leucosis, cattle tuberculosis, the leukocytes count and lymphocytes count among the cattle studied. A total of 662 animals were tested serologically and hematologically, by the techniques of double immunodiffusion in agarose gel and the white blood cell count with the total and differential leukocyte count, respectively, and 612 were evaluated immunoallergically by the tuberculin test. In the 15 herds examined, the prevalence of cattle that were positive to the AGID and tuberculin tests were $32.2 \%(213 / 662)$ and $14.1 \%(86 / 612)$, respectively. Analyzing the correlation between the variables total leukocytes and lymphocytes, we found that total leukocyte is highly related to the variable lymphocytes (72\%). The results in this study indicated that the diseases studied are widespread in the population studied, with significant levels of growth in leukemia, and infections of bovine leukosis virus (VLB) and Mycobacterium bovis are active and growing, with risk of impairment of the health of cattle herds, and, due to the zoonotic nature of bovine tuberculosis, of the health of people who work with cattle.
\end{abstract}

KEY WORDS: Mycobacterium bovis, VLB, complications, dairy cattle, Pernambuco.

\section{INTRODUÇÃO}

A leucose enzoótica dos bovinos (LEB) e a tuberculose (TB) são doenças infecto-contagiosas cosmopolitas, caracterizadas pela evolução crônica e pelos grandes prejuízos que determinam à pecuária bovina nacional ao comprometerem a performance produtiva dos rebanhos, reduzindo a produção, estabelecendo sucessivas condenações de carcaças em matadouros e restringindo o comércio de animais, além do aumento dos custos com serviços veterinários. A hipótese da intercorrência dessas doenças vem sendo postulada (MeLo, 1999;2000) sob a fundamentação de dois fatores que podem estar interferindo de forma interdependente e associada na etiopatogenia dessas doenças: o manejo sanitário

${ }^{2}$ Universidade Federal do Maranhão, Centro de Ciências Agrárias e Ambientais, Chapadinha, MA, Brasil. 
a que são submetidos os rebanhos eas características imunológicas do Vírus da Leucose Bovina (VLB).

Medidas sanitárias mais rigorosas, implementadas de acordo com o Regulamento Técnico do Programa Nacional de Controle e Erradicação da Brucelosee Tuberculose-PNCEBT, do Departamento de Defesa Animal do Ministério da Agricultura e do Abastecimento - MAPA, podem promover o redirecionamento deste importante setor produtivo brasileiro, desdeque seus objetivos sejam alcançados e as estratégias sanitárias efetivamente praticadas.

Outrossim, o papel do VLB no desencadeamento de bacterioses oportunistas de importância clínicoepidemiológica e em saúde pública, como a tuberculose, é desconhecido. Admite-se, entretanto, que o comprometimento da integridade do sistema imunitário orgânico pela ação imunodepressora do VLB, que penetra eincorpora-se no genoma linfócitário por tempo indeterminado (MusCoplat et al., 1974; WYERS, 1975; CASTRO et al., 1988), associado a evidências imunocitológicas de que infecta monócitos circulantes (HEENEY et al., 1992), também aumenta a susceptibilidade do hospedeiro a outras infecções (BURNY; MAMMERICKX, 1987). Adicionalmente, estresse do hospedeiro advindo de sua vida produtiva (lactação, maximização de ganho de peso) e, principalmente, de doenças intercorrentes, desempenha, provavelmente, importante papel no desencadeamento da replicação dos retrovírus no organismo infectado (WYERS, 1975), condiçãoclínico-imunitária queinclui VLBesua ampla disseminação nos rebanhos bovinos.

Nessecontexto potencialmente crítico, em que infeç̧ão e doença representam praticamente o mesmo risco na cadeia epidemiológica, uma realidade cada vez mais presente nos rebanhos é o alastramento da leucose, a iminência da instalação de um estado de enzootia da tuberculose, incluída pela Organização Mundial de Saúde entre as zoonoses emergentes (Cosıvi, 1998). É preciso, pois, a implementação sistemática de medidas sanitárias que visem o diagnóstico e o controle dessas enfermidades.

Diante do exposto, enfatizando a importância do conhecimento dessas enfermidades e a carência de pesquisas na literatura regional, principalmente sobre a tuberculose, realizou-se este estudo.

\section{MATERIAL E MÉTODOS}

O tamanho da amostra foi estabelecido em função de alguns critérios epidemiológicos, como tipo de exploração, categoria animal e a área geográfica, utilizando-se a técnica de amostragem preconizada pelo Centro Panamericano de Zoonoses (1988) e pelo Centro Panamericano de Febre Aftosa (Astudillo, 1979), relacionados ao estudo de prevalência das enfermidades crônicas infecciosas.
Com base em resultados preliminares (TENÓRIO, 2003), foi estabelecido $16,0 \%$ como a prevalência mínima estimada da infecção por vírus da leucose bovina na população a ser examinada, admitindo-se uma margem de erro de $20 \%$, depositando-se nesse resultado um grau de confiança de $95 \%$, desta forma, obteve-se 525 como número mínimo de amostras a serem testadas.

As amostras foram colhidas por meio de venopunção da jugular, após antisepsia com solução de álcool iodado a $2 \%$ e com auxílio de agulha descartável $40 \times 16 \mathrm{~mm}$, sendo acondicionadas em tubos de ensaio estéreis que permaneceram inclinados e em repouso para facilitar a retração do coágulo até o processamento laboratorial. Foram centrifugadas durante 15 minutos com força real de centrifugação igual a 5000G (gravidade) e o soro obtido foi transferido para tubos plásticos e armazenado em freezer à $-20^{\circ} \mathrm{C}$.

As amostras foram examinadas sorologicamente para LEB no Laboratório de Pesquisa em Clínica de Grandes Animais do Departamento de Medicina Veterinária da UFRPE.

Empregou-se a técnica da imunodifusão em gel de agar (IDGA) ou Radial Dupla de Ouchterlony (Miller; Van Der MaAten, 1975; 1977; Birgel, 1982), reconhecida mundialmente para detecção de anticorpos séricos específicos anti-VLB, por meio de um substrato de difusão gelatinoso, utilizando o antígeno glicoprotéico (gp 51), extraído do envelope do Vírus da Leucose Bovina.

Foi realizada a tuberculinização intradérmica cervical simultânea (teste cervical comparativo ou prova dupla comparada) com o objetivo de detectar bovinos com sensibilidade ou hipersensibilidade retardada às tuberculinas PPD aviária e bovina. Este estado imune, caracterizado por reações imunoalérgicas mediadas por linfócitos $\mathrm{T}$ e macrófagos (BIER, 1984), é indicador de prováveis portadores de infecções incipientes (OrGANIZACION..., 1968). Clinicamente, essas reações imunoalérgicas manifestadas pelos bovinos tuberculinizados foram avaliadas pela inspeção, palpação e cutimetria, atentando-se para possíveis aumentos de volume, sensíveis e de consistência firme, nos locais de inoculação das tuberculinas (ROSENBERGER, 1983; BLOOD; RAdOSTIS, 1991; DiRKSEn et al., 1993). O resultado final do teste foi estabelecido, decorridos 72 horas após a inoculação das tuberculinas, pelo cálculo da diferença da espessura da dobra da pele antes e após a inoculação, comparando-se com os valores de referência recomendados pelo Departamento de Defesa Animal, em seu Regulamento Técnico do Programa Nacional de Controle e Erradicação da Brucelose e Tuberculose Animal (BRASIL, 2006).

Os resultados obtidos foram analisados no pacote estatístico SPSS para Windows Versão 13.0 
(SAMPAIO, 2007), considerando um nível de significância de $5 \%(p \leq 1)$. Inicialmente foi procedida a análise decontigência usando-se o teste qui quadrado para verificar a existência de dependência entre as variáveis Leucose Enzoótica dos Bovinos (LEB) e Tuberculose Bovina (TB). Neste caso, quando o valor de $\mathrm{p}$ fosse menor do que $5 \%$ rejeitar-se-ia a hipótese de independência, indicando existência de relação (associação) entre essas duas variáveis.

\section{RESULTADOS E DISCUSSÃO}

Dos 662 animais, 612 foram avaliados imunoalergicamente, através do teste de tuberculinização, com exceção dos animais dos rebanhos 11 e 12, que não realizaram o diagnóstico imunoalérgico para tuberculose. Entretanto, as 662 amostras foram analisadas sorologicamente pela técnica de Imunodifusão dupla em gel de agarose (IDGA).

A prevalência de bovinos reagentes a imunodifusão nos 15 rebanhos examinados foi $32,1 \%$ (213/662), coeficiente para o qual a maioria dos rebanhos contribuiu com bovinos portadores de anticorpos anti-VLB, com exceção dos rebanhos 11 e 13 que não apresentaram animais sororreagentes (Tabela 1). Na Tabela 1 observa-se, também, que a distribuição dos índices de frequência de animais reagentes à infecção nos municípios, em ordem decrescente, foi: Itambé 53,3\% (24/45); Belo Jardim 41,9\% (76/181); Paudalho 38,8\% (47/121); Camaragibe 25,9\% (34/131); Arcoverde24,1\% (22/91); Recife 16,6\% (2/12); Canhotinho 16\% (8/50) e Vitória de Santo Antão 0,0\% (0/31).
Os critérios preconizados por SHETtigara (1986) permitiram avaliar que a maioria dos reba-nhos $(46,7 \%$ - $7 / 15)$ apresentou taxas de prevalência classificadas como de alta intensidade (R1, R2, R4, R5, R10, R14 e R15), média 33,3\% (5/15) (R6, R7, R8, R9 e R12), e apenas três deles (R3, R11 e R13), ou seja, $20,0 \%(2 / 15)$ apresentaram prevalência com classificação baixa.

Os resultados obtidos demonstram que a LEB mantém-se em índices significativamente crescentes desde o início da década de 90, quando se detectou pela primeira vez bovinos portadores de anticorpos anti-VLB (MELo, 1991), como um dos problemas sanitários mais relevantes para os rebanhos do Estado de Pernambuco, na medida em que sua prevalência de intensidadealta $(32,1 \%$-213/662) caracterizou-secomo crescente em relação às taxas encontradas por Melo (1991), por MENDES (2002) e TENÓRIO (2003), que foram de $15,1 \%(67 / 443), 14,6 \%(39 / 266)$ e $16 \%$ (96/600), respectivamente, ao examinarem amostras séricas procedentes de diversos rebanhos de bovinos leiteiros das quatro mesorregiões do Estado de Pernambuco.

A diferença observada na intensidade das taxas de prevalência entre os rebanhos examinados nesta pesquisa esteve associada, possivelmente, aos fatores clássicos de influência relacionados fundamentalmente ao manejo, na gênese da doença e em sua dinâmica clínico-epidemiológica.

Deum modogeral, a intensidade das prevalências variou em função do refinamento racial ou do grau de mestiçagem dos rebanhos. Os rebanhos tenderam a apresentar taxas com variação de média à alta intensidade, constituídos por animais com fenótipos de Girolandos.

Tabela 1 - Distribuição das taxas de prevalência de bovinos sororreagentes à imunodifusão para Leucose, em rebanhos leiteiros criados no Estado de Pernambuco.

\begin{tabular}{|c|c|c|c|c|c|}
\hline \multirow{2}{*}{ Rebanho } & \multirow{2}{*}{ Município } & \multicolumn{4}{|c|}{ Leucose Enzoótica Bovina } \\
\hline & & Positivos (\%) & Inconclusivos (\%) & Negativos (\%) & Total \\
\hline 1 & Paudalho & $47(38,8)$ & - & $74(61,1)$ & 121 \\
\hline 2 & Arcoverde & $12(31,5)$ & - & $26(68,4)$ & 38 \\
\hline 3 & Arcoverde & $1(7,6)$ & - & $12(92,3)$ & 13 \\
\hline 4 & Belo Jardim & $16(38,0)$ & - & $26(61,9)$ & 42 \\
\hline 5 & Arcoverde & $4(30,7)$ & - & $9(69,2)$ & 13 \\
\hline 6 & Arcoverde & $5(18,5)$ & - & $22(81,4)$ & 27 \\
\hline 7 & Camaragibe & $19(29,6)$ & - & $45(70,3)$ & 64 \\
\hline 8 & Recife & $2(16,6)$ & - & $10(83,3)$ & 12 \\
\hline 9 & Camaragibe & $15(22,3)$ & - & $52(77,6)$ & 67 \\
\hline 10 & Itambé & $24(53,3)$ & - & $21(46,6)$ & 45 \\
\hline 11 & Canhotinho & $0(0,0)$ & - & $17(100)$ & 17 \\
\hline 12 & Canhotinho & $8(24,2)$ & - & $25(75,7)$ & 33 \\
\hline 13 & Vitória de Santo Antão & $0(0,0)$ & - & $31(100,0)$ & 31 \\
\hline 14 & Belo Jardim & $48(47,5)$ & $7(6,9)$ & $46(45,5)$ & 101 \\
\hline 15 & Belo Jardim & $12(31,5)$ & $3(7,8)$ & $23(60,5)$ & 38 \\
\hline & Total & $213(32,1)$ & $10(1,5)$ & $439(66,3)$ & 662 \\
\hline
\end{tabular}


Tabela 2 - Distribuição das taxas de prevalência de bovinos reagentes à tuberculinização em rebanhos leiteiros criados no Estado de Pernambuco.

\begin{tabular}{|c|c|c|c|c|c|}
\hline \multirow{2}{*}{ Rebanho } & \multirow{2}{*}{ Município } & \multicolumn{4}{|c|}{ Tuberculose } \\
\hline & & Positivos (\%) & Inconclusivos (\%) & Negativos (\%) & Total \\
\hline 1 & Paudalho & $36(29,7)$ & $17(14,0)$ & $68(56,1)$ & 121 \\
\hline 2 & Arcoverde & $10(26,3)$ & $5(13,1)$ & $23(60,5)$ & 38 \\
\hline 3 & Arcoverde & $2(15,3)$ & $4(30,7)$ & $7(53,8)$ & 13 \\
\hline 4 & Belo jardim & $1(2,3)$ & $2(4,7)$ & $39(92,8)$ & 42 \\
\hline 5 & Arcoverde & $0(0,0)$ & $2(15,3)$ & $11(84,6)$ & 13 \\
\hline 6 & Arcoverde & $1(3,7)$ & $2(7,4)$ & $24(88,8)$ & 27 \\
\hline 7 & Camaragibe & $0(0,0)$ & $7(10,9)$ & $57(89,0)$ & 64 \\
\hline 8 & Recife & $1(8,3)$ & $2(16,6)$ & $9(75,0)$ & 12 \\
\hline 9 & Camaragibe & $12(17,9)$ & $0(0,0)$ & $55(82,0)$ & 67 \\
\hline 10 & Itambé & $9(20,0)$ & $0(0,0)$ & $36(80,0)$ & 45 \\
\hline 11 & Canhotinho & NR & NR & NR & NR \\
\hline 12 & Canhotinho & NR & NR & NR & NR \\
\hline 13 & Vitória de Santo Antão & $0(0,0)$ & $0(0,0)$ & $31(100)$ & 31 \\
\hline 14 & Belo Jardim & $11(10,8)$ & $11(10,8)$ & $79(78,2)$ & 101 \\
\hline 15 & Belo Jardim & $3(7,8)$ & $1(2,6)$ & $34(89,4)$ & 38 \\
\hline & Total & $86(14,0)$ & $53(8,6)$ & $473(77,2)$ & 612 \\
\hline
\end{tabular}

NR = Não Realizado.

Reconhece-se a raça como um atributo que interage em condições naturais, de forma indissociável, com as normas de criação. Classicamente, têm-se estabelecido que a doença ocorra mais no gado leiteiro refinado (raças leiteiras) por ser manejado de forma mais intensiva, que origina lotação exagerada das criações, além de ser submetido a manipulações tecnológicas, que mal aplicadas, facilitariam a transmissão horizontal (principalmente as formas iatrogênicas) ou vertical (transplacentária) do VLB.

A introdução de animais importados de outros estados, principalmente das regiões Sul e Sudeste, especialmente de São Paulo e de Minas Gerais, onde predominam altas taxas de prevalência da leucose, certamente é um dos fatores de influência na elevação da positividade da maioria dos rebanhos examinados neste estudo, especialmente devido à ausência de uma legislação vigente que obrigue a realização de exames de LEB, uma vez que esses estados, sabidamente, apresentam significativas taxas de prevalência da LEB, com valores médios de $38,0 \%$, podendo variar, em algumas situações, de 26,7 a 70,9 \% (D'ANGELINo et al., 1998; Melo, 1999; CAmArgos et al., 2002; AzEDO, 2007).

O rodízio intenso de animais nesses rebanhos e a inadequação do manejo sanitário podem, por falha de execução, ter condicionado uma maior disseminação da infecção. Esses aspectos do manejo atuam como fatores de risco, que predispõem à proliferação da infecção pela transmissão iatrogênica do VLB, como tratamento sistêmico, colheitas e transfusões de sangue, práticas inadequadas de vacinação, vermifugações, castrações, descornas e palpação retal (RosenBerger, 1961; 1968; WILESMITH, 1980; BiRgel et al., 1982; BRIGHTLING; RADOSTITS, 1983; LORENZ; STAUB, 1987; HOSPKINS; DiGIACOMO, 1997).

Os resultados obtidos neste estudo demonstraram que a disseminação da LEB nos 15 rebanhos estudados, considerando-se a semelhança do manejo implementado na maioria deles, ocorreu, provavelmente, pelo intenso fluxo de animais entre os rebanhos, bem como pela introdução de animais importados de outros Estados sem obedecer a rígidos critérios de sanidade, principalmente na região Sudeste, destacando-se São Paulo e Minas Gerais, que apresentam historicamente elevados índices da LEB (Gomeset al., 1985; Birgel et al., 1988; D' ANGELINO, 1991; Melo, 1999). Soma-se a isso o desconhecimento dos produtores sobre a doença, assistência médicoveterinária deficiente, além dos efeitos negativos advindos da desestruturação de órgãos oficiais do Estado envolvidos com a sanidade animal, não havendo efetivo para a erradicação desta enfermidade, interferindo de forma negativa na produtividade dos rebanhos.

Em relação à tuberculose, a prevalência de bovinos imunoalérgicos positivos à tuberculinização nos 13 rebanhos examinados foi $14,0 \%$ (86/612), coeficiente para o qual 77,0\% (10/13) dos rebanhos contribuíram com pelo menos um animal positivo, com exceção dos rebanhos 5,7 e 13 que não apresentaram animais positivos (Tabela 2). Na Tabela 2 observa-se, também, que a distribuição dos índices de frequência de animais reagentes à infecção em Pernambuco, nos municípios, em ordem decrescente, foi: Paudalho 30,0\% (36/121); Itambé 20,0\% (9/45); Arcoverde 14,2\% (13/91); Camaragibe 9,2\% (12/131); Belo Jardim 8,3\% (15/181); Recife 8,3\% (1/12); e Vitória 
de Santo Antão 0,0\% (0/31). A distribuição dessas vacas reagentes ao teste da tuberculina, positivas e inconclusivas, em praticamente todos os rebanhos examinados, com exceção de três rebanhos (R5 e R7 positivo), (R9 e R10 - inconclusivo) e o Rebanho 13 que não apresentou nenhum animal positivo e inconclusivo, é uma evidência clínico-epidemiológica da ampla disseminação da infecção pelo $M$. bovis na região estudada.

Os critérios preconizados por SHETTIGARA (1986) permitiram avaliar quea maioria dos reba-nhos $53,8 \%$ (7/13), apresentou taxas de prevalência classificadas como de baixa intensidade (R4, R5, R6, R7, R8, R13 e R15), média 46,1\% (6/13) (R1, R2, R3, R9, R10 e R14), e nenhum dos rebanhos avaliados apresentaram prevalência com classificação alta.

Os resultados estudados demonstram que a tuberculose encontra-se em índices significantes nos rebanhos bovinos avaliados, como um problema sanitário de grande importância para os rebanhos do Estado de Pernambuco, na medida em que sua prevalência de intensidade média $(14,0 \%$ - 86/612) caracterizando-se como crescente em relação aos índices oficiais disponíveis para o País, cuja prevalência média em bovinos foi estimada em $1,5 \%$ no período de 1989-1998 (BrASIL, 2001).

Esse contraste já havia sido observado entre as informações oficiais e os resultados obtidos em um estudo de prevalência realizado em vários rebanhos leiteiros do Estado deSão Paulo que demonstrou que $20 \%$ das vacas $(153 / 766), 114$ positivas e 39 suspeitas, reagiram à tuberculinização, com variação de $0 \%$ a $62,5 \%$, destacando-se algumas taxas elevadas de $31,6 \%, 50 \%$ e 53,3 (Melo, 1999).

São também muito superiores aos estimados para o Estado de Pernambuco. Dados não consolidados, tabulados a partir de relatórios enviados por veterinários que atuam em vários municípios do Estado, catalogados na Delegacia Federal em Pernambuco/ Seção de Sanidade Animal, demonstraram que a prevalência média da tuberculose bovina foi de 5,7\% (9.93/17.248). Recentemente, ainda em Pernambuco, Melo et al. (2005) detectaram que 13,6\% (3/22) das vacas, submetidas ao TCC, reagiram positivamente. Respeitadas as devidas proporções, esses contrastes de resultados podem indicar que as estimativas da prevalência da tuberculose bovina precisam ser revistas e atualizadas em vários setores da pecuária nacional.

Quanto à intensidade das reações imunoalérgicas, alguns autores a utilizam como critério para qualificar as reações manifestadas por bovinos à tuberculinização simples, com inoculação exclusiva da tuberculina bovina, em forte ou fracamente positivas, admitindo ser esta uma das características da ocorrência de reações inespecíficas nos rebanhos (LANGENEGGER et al., 1981). Sua importância maior, entretanto, parece estar associada ao emprego da tuberculinização intradérmica comparada, que possibilita detectar com mais segurança bovinos sensibilizados imunologicamente pelocontato ou por infecções produzidas por micobactérias saprófitas ou patogênicas facultativas (micobacterioses) (CASTRO; Nemoto, 1972; CorrêA; CORRÊA, 1973; LANGENEGGer; LANGENEGGER, 1976).

O quadro potencialmente crítico, caracterizado pela instalação de um estado de enzootia da tuberculose nos rebanhos bovinos estudados representa a deterioração das condições de saúde da maioria dos rebanhos examinados, pertencentes basicamente a pequenos produtores. Decorrem do processo de desmonte de alguns serviços de sanidade animal, particularmente os sistemas de vigilância epidemiológica, onde os criadores, por não poderem ou não saber recorrer a mecanismos alternativos de atenção veterinária, frequentemente submetem seus animais a manejo geral falho, particularmente em seus aspectos sanitários, o que propicia o convívio íntimo e prolongado de bovinos doentes, fontes naturais e potenciais disseminadores de agentes infecciosos, com animais sadios, continuamente expostos ao risco de infecções. Esses rebanhos têm, possivelmente, a performance produtiva comprometida pela diminuição da produção leiteira, sucessivas condenações de carcaças em matadouros e restrições comerciais de animais, além do aumento dos custos com serviços veterinários.

Nos 15 rebanhos examinados, as prevalências de bovinos que apresentaram positividade aos testes IDGA e tuberculina foram 32,1\% (213/662) e 14,0\% (86/612), respectivamente. A maioria dos rebanhos $(86,6 \%$ - 13/15) contribuiu com vacas reagentes para a composição destes índices, destacando-se taxas elevadas de 48,8 (22/45) e 29,7\% (36/121) para LEB eTB, respectivamente. Os bovinos que manifestaram reações inconclusivas a um ou a ambos os testes corresponderama 8,6\% (57/662). A prevalência debovinos reagentes, para LEB e/ou TB, foi 45,1\% (299/662), distribuindo-seesteíndicenos municípios, em ordem decrescente: Itambé 68,8\% (31/45), Paudalho 68,5\% (83/121), Belo Jardim 50,2\% (91/181), Arcoverde $39,5 \%$ (36/91), Camaragibe 35,1\% (46/131), Recife 25\% (3/12), Canhotinho 16\% (8/50), Vitória deSanto Antão 0,0\% (0/31). A estratificação dos rebanhos pela intensidade da prevalência evidenciou que 46,6\% (7/15) (R1, R2, R4, R5, R7, R10 e R15) deles apresentaram intensidade alta, 33,3\% (5/15) (R3, R6, R8, R12 e R14) média e apenas 20\% (3/15)(R9, R11 e R13) intensidade baixa.

Positividade aos testes IDGA e TCC indica presença de bovinos potencialmente infectados e fontes naturais do VLB e/ou do M. bovis nos rebanhos. Infecção e doença representam um mesmo risco na cadeia epidemiológica da LEB e da TB, então, esses 
bovinos, portadores inaparentes de infecção, são elementos precursores da gênese das duas doenças na população examinada neste estudo, sendo seu reconhecimento indispensável para projeção do problema, possibilitando o mapeamento de focos e a antecipação de medidas mais efetivas de combate por meio de programas sanitários oficiais. Neste sentido, praticamente a metade da população examinada (45,1\% - 299/662) encontra-se com o estado de saúde comprometido, especialmente $12,3 \%$ (37/299) das vacas que apresentaram positividade simultânea aos dois testes, caracterizando um estado de co-infecção.

Historicamente, a dinâmica da infecção pelo VLB em rebanhos do Estado de Pernambuco apresentou um recrudescimento expressivo, evidenciada pelo confronto da soroprevalência estabelecida neste estudo $32,1 \%(213 / 662)$ com as estimadas em estudos anteriores (15,4\% - 202/1308) (Melo, 1991; MeNDES, 2002; TENÓRIO, 2003).

Considerando o caráter irreversível da infecção pelo VLB e M. bovis, a inclusão da LEB e TB na lista de notificação obrigatória da Organização Mundial de Sanidade Animal (OfFICE..., 2008) e as medidas previstas no PNCBT (BRASIL, 2006) para o saneamento de rebanhos, além do caráter zoonótico da $\mathrm{TB}$, metade das vacas examinadas neste estudo deve ser eliminada de seus rebanhos de origem, o que implica em grandes prejuízos para os produtores e, conseqüentemente, para a pecuária leiteira do Estado de Pernambuco. Isto representa a deterioração das condições de saúde da maioria dos rebanhos examinados, pertencentes basicamente a pequenos produtores, os quais, ao recorrerem a mecanismos alternativos de atenção veterinária ou tentarem obter ganhos comerciais ou melhorarem geneticamente seus rebanhos, promovem o trânsito e tráfico de bovinos infectados entre suas criações, fontes naturais e potenciais disseminadores de VLB e M. bovis. Esses rebanhos, por isso, apresentam diminuição da produtividade leiteira, sucessivas condenações de carcaças em matadouros e restrições comerciais de animais, além do aumento dos custos com serviços veterinários.

Os bovinos, além de serem introduzidas sistematicamente nos rebanhos para renovação ou formação dos plantéis, representam um risco singular na gênese da leucose enzoótica dos bovinos nos rebanhos examinados, pois, além de transmitirem o VLB por via horizontal, poderiam o transmitir por via transplacentária ou vertical, como foi comprovado pelos estudos de vários pesquisadores (FERRER; Diglio, 1976; FerRer et al., 1980; Evermann etal., 1987).

Finalmente, deve-se destacar que o R1, localizado na Mesorregião da Mata Pernambucana, dentre todos examinados na pesquisa, foi o rebanho que concentrou maior número de bovinos reagentes às duas doenças estudadas, com prevalências de
$38,8 \%(47 / 121)$ e $29,7 \%(36 / 121)$ para leucose e tuberculose, respectivamente. Neste rebanho, embora estasticamente não se possa assegurar que houve intercorrência entre as doenças, provavelmente, inúmeros fatores comuns, intenso fluxo de animais, introdução de animais importados de outros estados, desconhecimento do produtor sobre as doenças e condições edafo-climáticas, interagiram entre si na etiopatogenia das doenças estudadas. Na análise dos resultados, observou-se que o animal que apresentou LEB negativa apresentou TB negativa em $87,3 \%$ dos casos.

\section{CONCLUSÕES}

Os resultados obtidos nesta pesquisa, considerando a análise e interpretação dos aspectos sanitários da leucose e da tuberculose dos bovinos nos rebanhos examinados, permitiram concluir que essas enfermidades encontram-se amplamente disseminadas na população estudada, com crescimento em níveis significativos da leucose. $\mathrm{E}$ as infecções pelo VLB e M. bovis encontram-se ativas e em expansão, com risco iminente do comprometimento da saúde dos rebanhos bovinos e, pelo caráter zoonótico da tuberculose bovina, das pessoas que lidam com os bovinos. A infecção simultânea de muitos animais sugere que VLB desempenha algum papel no desencadeamento da tuberculose bovina.

\section{REFERÊNCIAS}

ASTUDILLO, V.M. Encuesta por muestra para estudios epidemiologicos en populaciones animales. Rio de Janeiro: Centro Panamericano de Febre Aftosa, 1979. 60p. (Serie de Manuales Didáticos n. 12).

AZEDO, M.R. Influência da leucose enzoótica bovina na atividade oxidativa dos leucócitos. 2007, 151 f. Dissertação (Mestrado em Clínica Médica) - Faculdade de Medicina Veterinária e Zootecnia, Universidade de São Paulo, São Paulo, 2007.

BIER, O. Microbiologia e imunologia. 3.ed. Rio de Janeiro: Melhoramentos, 1984. p.1234.

BIRGEL, E.H. Leucose linfática enzoótica dos bovinos adultos: aspectos clínicos e diagnóstico. In: SOCIEDADE PAULISTA DE MEDICINA VETERINÁRIA. Patologia clínica veterinária. São Paulo: Sociedade Paulista de Medicina Veterinária, 1982. p.249-260.

BIRGEL, E.H.; BENESI, F.J; D' ANGELINO, J.L.; HAGIWARA, M.K.; PRADO, M.S.S. Características leucométricas do sangue de bovinos de rebanhos acometidos por leucose enzoótica dos bovinos adultos. In: SEMANA DE VETERINÁRIA DA FACULDADE DE MEDICINA VETERI- 
NÁRIA E ZOOTECNIA DA UNIVERSIDADE DE SAO PAULO, 1.,1982, Campinas. Anais. Campinas, 1982. p.73

BIRGEL, E.H.; D'ANGELINO, J.L.; GARCIA, M.; MARÇAL, W.S. Estudo preliminar sobre a ocorrência da leucose dos bovinos adultos em animais criados na região de Campinas. In: CONFERENCIA ANUAL DA SOCIEDADE PAULISTA DE MEDICINA VETERINARIA, 43. 1988, Campinas. Anais. Campinas: SPMV, 1988. p.30.

BLOOD, D.C.; RADOSTITS, O.M. Clínica veterinária. Rio de Janeiro: Guanabara Koogan, 1991. 1263p.

BRASIL. Ministério da Agricultura, Pecuária e Abastecimento. Regulamento Técnico do Programa Nacional de Combate e Erradicação da Brucelose e Tuberculose. Brasília: MAPA, 2001.

BRASIL. Ministério da Agricultura, Pecuária e Abastecimento. Departamento de Defesa Animal. Programa Nacional de Controle e Erradicação da Brucelose e Tuberculose (PNCEBT) - Manual Técnico. Brasília, 2006. 132p.

BRIGHTLING, P.; RADOSTITS, O.M. Bovine leukosis virus infection in a dairy herd in Saskatchewan. Canadian Veterinary Medicine. v.44, p.168-175, 1983.

BURNY, A.; MAMMERICKX, M. (Ed.). Enzootic bovine leukosis and bovine leukemia virus. Developments in Veterinary Virology. Boston, 1987. 283p. (Series III).

CAMARGOS, M.F.; MELO, C.B.; LEITE, R.C.; STANCEK, D.; LOBATO, Z.I.P.; ROCHA, M.A.; SOUZA, G.N.; REIS, J.K.P. Frequência de soropositividade para a leucose enzoótica bovina em rebanhos de Minas Gerais. Ciência Veterinária nos Trópicos, v.5, n.1, p.20-26, 2002.

CASTRO, A.F.P.; NEMOTO, H. Occurrence of atypical mycobacteria in the lymph nodes of apparently healthy slaugh tered cattle in São Paulo, Brazil. Reviews Microbiology, v.3, n.2, p75-78, 1972.

CASTRO, N.H.C.; WALTER, J.; SANTOS, R.C.S.; D'ANGELINO, J.L.; BENESI, F.; BIRGEL, E.H.; BEÇAK, W. Cytogenetics study of cattle affected by persistent lymphocythosis. Journal of Veterinary Medicine, v.35, p.380-384, 1988.

CENTRO PANAMERICANO DE ZOONOSIS. Procedimentos para estudios de prevalencia de enfermedades cronicas por muestreo. Buenos Aires: CEPANZO, 1988. 33p.

CORRÊA, C.N.M.; CORRÊA, W.M. Micobactérias isoladas de bovinos e suínos em São Paulo, Brasil. Arquivos do Instituto Biológico, São Paulo, v.40, n.3, p.205-208, 1973.

COSIVI, O.; GRANGE, J. M.; DABORN, C. J.; RAVIGLIONE, M. C.; FUGIKURA, T.; COUSINS, D.; ROBINSON, R. A.; HUCHZERMEYER, H. F. A. K.; KANTOR, I.; MESLIN, F. X. Zoonotic tuberculosis due to Mycobacterium bovis in developing countries. Emerging Infectious Diseases, v.4, n.1, p.59-70, 1998.
D’ANGELINO, J. L. Leucose enzoótica dos bovinos. Estudo retrospectivo da performance produtiva e reprodutiva de animais infectados e não infectados. 1991. 85p. Tese (LivreDocência) - Faculdade de Medicina Veterinária e Zootecnia, Universidade de São Paulo, São Paulo, 1991.

D'ANGELINO, J. L.; GARCIA, M.; BIRGEL, E. H. Epidemiological study of enzootic bovine leukosis in Brazil. Tropical Animal Health and Production. v.30, p. 13-15, 1998.

DIRKSEN, G.; GRUNDER, H.; STOBER, M. ROSENBERGER. Exame clínico dos bovinos. Rio de Janeiro: Guanabara Koogan, 1993. 419p.

EVERMANN, J.F.; DIGIACOMO, R.F.; HOPKINS, S.G. Bovine leukosis virus: understanding viral transmission and the methods of control. Veterinary Medicine, v.82, n.10, p.1051-1058, 1987.

FERRER, J.F.; DIGLIO, C.A. Development of on in vitro infectivity assay for the $C$ type bovine leukemia virus. Cancer Research, v.36, p.1068-1073, 1976.

FERRER, J.F.; MARSHAK, R.R.; ABT, D.A.; KENYON, S.J. Relationship between lynphosarcoma and persistente lymphocytosis in cattle: a review. Journal of the American Medical Association, v.175, p.705-708, 1980.

GOMES, M.; MOOJEN, V.; FERNADES, J. C. T.; FERREIRO, L. Detecção de anticorpos séricas contra o virus da Leucose Enzoótica Bovina (VLEB) em bovinos no Estado do Rio Grande do Sul. Arquivos da Faculdade de Veterinária da Universidade Federal do Rio Grande do Sul. v.13, p.15-22, 1985.

HEENEY, J.L.; VALLI, P.J.; JACOBS, R.M.; VALLI, V.E. Evidence for bovine leukemia virus infection of peripheral blood monocytes and limited antigen expression in bovine lymphoid tissue. Laboratory Investigation, v.66, n.5, p.608-617, 1992.

HOSPKINS, S.G.; DiGIACOMO, R.F. Natural Transmission of Bovine Leukemia Virus in Dairy and Beef Cattle. Veterinary Clinics of North America Food Animal Practice - Food Animal Retroviruses. v.13, n.1, p.107-128, 1997.

LANGENEGGER, J.; LANGENEGGER, C.H. Micobactérias atípicas isoladas de amígdalas e linfonodos de bovinos. Pesquisa Veterinária Brasileira, v.11, p.37-42, 1976. (Série Veterinária).

LANGENEGGER, J.; LANGENEGGER, C.H.; MOTA, P.M.P.C.; LEITE, R.C. Reações inespecíficas no diagnóstico alérgico da tuberculose bovina. Pesquisa Veterinária Brasileira, v.1, n.4, p.45-49, 1981.

LORENZ, R.J.; STRAUB, O.C. The epidemiology of enzootic bovine leukosis. In: BURNY, A.; MAMMERICKX, M. (Ed.). Enzootic bovine leukosis and bovine leukemia virus. Boston: Martinus Nijhoff, 1987. p.51-68. 
MELO, L.E.H. Leucose Enzoótica dos Bovinos. Prevalência da infecção em rebanhos leiteiros criados no Agreste Meridional do Estado de Pernambuco. 1991. 102p. Dissertação (Mestrado) - Faculdade de Medicina Veterinária e Zootecnia, Universidade de São Paulo, São Paulo, 1991.

MELO, L.E.H. Avaliação da intercorrência entre Leucose Enzoótica, Tuberculose e Leptospirose dos bovinos em rebanhos produtores de leite C do Estado de São Paulo. 1999, 128 p. Tese (Doutorado) - Faculdade de Medina Veterinária e Zootecnia, Universidade de São Paulo São Paulo, 1999.

MELO, L.E.H.; D'ANGELINO, J.L.; CASTRO, R.S.; FREITAS, A.A.; SILVA, F.F.; SANTOS, N.V.M.; RÊGO, E.W.; SCHALCH, U.M.; PACHECO, J.C.G.; BENATTI, L.A.T.; TENÓRIO, T.G.S. Avaliação da Intercorrência entre Leucose Enzoótica, Tuberculose e Leptospirose dos Bovinos em Rebanhos Leiteiros de São Paulo. In: CONGRESSO BRASILEIRO DE MEDICINA VETERINÁRIA, 27., 2000, Águas de Lindóia. Anais. Águas de Lindóia, 2000. p.24.

MELO, M.T.; SALDANHA, S.V.; MELO, L.E.H.; EVÊNCIO-NETO, J.; TENÓRIO, T.G.S.; FERNADES A.C.C. Ocorrência da tuberculose caprina no Estado de Pernambuco. Arquivos do Instituto Biológico, São Paulo, v.72, n.2, p.25, 2005. Suplemento 2. Trabalho apresentado na REUNIÃO ANUAL DO INSTITUTO BIOLÓGICO, 18., 2005, São Paulo. Resumo 013.

MENDES, E. I. Aspectos Sorológicos e Hematológicos como recursos auxiliares ao diagnóstico da Leucose Enzoótica dos Bovinos em rebanhos leiteiros de Pernambuco. 2002. 47p. Dissertação (Mestrado) - Universidade Federal Rural de Pernambuco, Recife, 2002.

MILLER, J. M.; VAN DER MAATEN, M.J. Serological Detection of Bovine Leukemia Virus infection. Procedings of the 2nd CEC Seminar on Bovine Leukosis. Copenhagem, 1975. p.17-18.

MILLER, J.M.; VAN DER MAATEN, M.J. Use of glycoprotein antigen in the imunodiffusion test for bovine leukemia virus antibodies. European Journal of Cancer, v.13, p 1369-1375, 1977.

MUSCOPLAT, C.C.; ALHAJI, I.; JOHNSON, D.W.; POMEROY, K.A.; OLSON, J.M.; LARSON, V.L.; STEVENS, J.B.; SORENSEN, D.K. Characteristics of lymphocyte responses to phytomitogens: comparison of responses of lymphocytes from normal and lymphocitotic cows. American Journal of Veterinary Research, v.35, p.1053-1055, 1974.

OFFICE INTERNATIONAL DES ÉPIZOOTIES. CÓDIGO ZOOSANITÁRIO INTERNACIONAL. 2008. Disponível em: <http:/ / www.oie.int>. Acesso em: 11 jan. 2008, on line.

ORGANIZACION MUNDIAL DE LA SALUD. Comité de expertos de la OMS en patrones biológicos: 20. Ginebra: Informe, 1968. 104p. (Serie Informes técnicos, n.384).

ROSENBERGER, G. Enfermidades de los bovinos. Buenos Aires: Hemisfério Sul, 1983. v.1/2. 1154p.

ROSENBERGER, G. Die wissenschaftlichen Grundlagen zur Bekampfung der Rinderleukose. Zentralblatt fur Veterinarmedizin, B. v.15. p.193-199, 1968.

ROSENBERGER, G. Leukose des Rindes. Berlin: Deutsche Akademie der Landwirtschaftzwissenschaften, 1961. p.33-45. (Tagungsberichte, 49).

SAMPAIO, I.B.M. Estatística aplicada à experimentação animal. 3.ed. Belo Horizonte: FEP-MVZ, 2007. 265p.

SHETTIGARA, P.T. Eradication of bovine leukemia virus infection in commercial dairy herds using the agar gel immuno-diffusion test. Canadian Journal of Veterinary Research, v.50, p.221-226, 1986.

TENÓRIO, T.G.S. Aspectos sanitários da Leucose Enzoótica, da Leptospirose e da Brucelose dos Bovinos em rebanhos leiteiros de Pernambuco. 2003, Dissertação (Mestrado) - Universidade Federal Rural de Pernambuco, Recife, 2003.

WILESMITH, J.W. Algumas observações sobre a epidemiologia da infecção por vírus da leucose bovina num grande rebanho leiteiro. Trad. de Paulo Ponce de Leon Filho e Lúcio José Gomes Pereira. Recife, Serviço de Defesa Sanitária Animal, 1980. 16p. (Epidemiologia e Medicina Veterinária Preventiva, 1).

WYERS, M. Rappel sur les oncornavirus des animaux. Recueil de Médecine Vétérinaire, v.151, n.3, p.153-163, 1975.

Recebido em 14/9/09

Aceito em 8/12/10 